\title{
Comparison between cigarette smoke-induced emphysema and cigarette smoke extract-induced emphysema
}

\author{
Zhi-Hui He ${ }^{1}$, Ping Chen ${ }^{2 *}$, Yan Chen ${ }^{2,3^{*}}$, Sheng-Dong He${ }^{2}$, Ji-Ru Ye ${ }^{2}$, Hong-Liang Zhang ${ }^{2}$ and Jun $\mathrm{CaO}^{4}$
}

\begin{abstract}
Background and objective: Emphysema is the main pathological feature of COPD and also is the focus of the related research. Although several emphysema animal models have been established, exact comparison of findings is seldom. The present study aimed to compare cigarette smoke (CS) exposure-induced emphysema model and intraperitoneal injection of cigarette smoke extract (CSE)-induced emphysema model to evaluate the effectiveness of the two different modeling methods.
\end{abstract}

Methods: Six-week-old male C57BL/6 J mice were used and randomly divided into two groups: CS exposure and intraperitoneal injection of CSE. Each group was subdivided into two subgroups: control and CS or CSE. Lung function, mean linear intercept (MLI), destructive index (DI), apoptotic index (Al), total and differential cells count in broncholavolar lavage fluid (BALF), SOD and IL-6 concentration in serum were measured.

Results: Compared with their respective controls, lung function was significantly decreased in CS and CSE groups $(P<0.01) ; \mathrm{MLI}, \mathrm{Dl}$, and $\mathrm{Al}$ of lung tissue were significantly higher in CS and CSE groups $(P<0.01)$; total number of leukocytes, the number and percentage of neutrophils (NEUs), and the number of macrophages (MAC) in BALF were significantly higher in CS and CSE groups $(P<0.01)$; SOD concentration in serum was significantly decreased in CS and CSE groups $(P<0.01)$; IL-6 concentration in serum was significantly increased in in CS and CSE groups $(P<0.01)$. There was no significant difference between CS group and CSE group in any of the parameters described above.

Conclusions: Both CS exposure and intraperitoneal injection of CSE could induce emphysema and the effectiveness of the two different modeling methods were equal.

Keywords: Animal, Chronic obstructive pulmonary disease (COPD), Emphysema, Model

\section{Introduction}

Chronic obstructive pulmonary disease (COPD) is a progressive chronic respiratory disease of human beings characterized by not fully reversible airflow limitation. It is mainly caused by cigarette smoke and is the fourth leading cause of death worldwide. According to the World Health Organization, its prevalence will double by 2020 [1] and it will become the third leading cause of death worldwide [2]. But the mechanism of COPD is not

\footnotetext{
* Correspondence: pingchen0731@sina.com; chenyan99727@163.com ${ }^{2}$ Department of Respiratory Medicine, The Second Xiangya Hospital, Central-South University, Changsha, Hunan 410011, China

${ }^{3}$ Division of Respiratory Disease, Department of Internal Medicine, The Second Xiangya Hospital, Central-South University, Changsha, Hunan 410011, China

Full list of author information is available at the end of the article
}

completely illuminated. Direct research on human body was limited because of the anthropic ethics. Therefore, research on animal model is particularly important. Emphysema is the main pathological feature of COPD and also is the focus or hotspot of research which focuses on the mechanism of COPD.

Although several emphysema animal models have been established, exact comparisons of findings from various groups are difficult because different methods, different types of cigarettes, different doses of cigarette smoke, instruments, exposure protocols and a wide variety of animals are used. Some of the models were insufficient in quantitative evaluation. Smoking is the most important risk factor for emphysema. Cigarette smoke (CS) is a mixture of more than 4,000 different chemical 
compounds, such as free radicals, toxins, and electrophiles, etc. $[3,4]$. The CS extract (CSE) contains nearly all of the compounds inhaled by smokers. In resent years, animal model of emphysema was also established by intraperitoneal injection of CSE [5,6]. The present study aim to investigate whether the effectiveness of CS exposure and intraperitoneal injection of CSE on emphysema were equal. We used the same cigarettes and animals, and compared CS exposure-induced emphysema and intraperitoneal injection of CSE-induced emphysema in lung function and histomorphology, apoptosis of alveolar septum cells, total and differential cell counts in broncholavolar lavage fluid (BALF), SOD and IL-6 concentrations in serum.

\section{Materials and methods Animals}

Forty-eight 6-week-old male C57BL/6 J mice (Wt: $20.26 \pm$ $2.34 \mathrm{~g}$ ) were randomly enrolled in this study and randomly divided into two groups: CS exposure group (group 1) and intraperitoneal injection of CSE group (group 2). Each group was further divided into two subgroups: control (group N) and CS or CSE (group C), named N1, C1, N2, $\mathrm{C} 2$ respectively ( $\mathrm{n}=10$ per subgroup). All animals were provided by Shanghai Laboratory Animal Center of Chinese Academy of Sciences (SLACCAS, Shanghai, China) and fed in a clean unit at $23^{\circ} \mathrm{C} \sim 25^{\circ} \mathrm{C}, 50 \% \sim 60 \%$ humidity, 12 hours (h) rhythm of light and dark. They were provided free access to water and food. The Second Xiangya Hospital Experimental Animal Center of Central South University was responsible for feeding.

The study was approved by the Institutional Review Board of Central-South University and conformed to the guiding principles for research involving animals and human beings [7].

\section{Preparation of CSE}

CSE was prepared using a technique described previously [8] with some modification. Briefly, one non-filtered FuRong cigarette (Tar: $13 \mathrm{mg}$, Nicotine: $1.0 \mathrm{mg}$, Carbon Monoxide: $14 \mathrm{mg} /$ cigarette, China Tobacco Hunan Industrial Co., Ltd., Changsha, China) was burned and the smoke passed through $4 \mathrm{ml}$ of phosphate-buffered saline (PBS) by connecting to a vacuum pump with a constant pressure of $-0.1 \mathrm{Kpa}$. This solution was used for intraperitoneal injection after filtering through a filter with $0.22-\mu \mathrm{M}$ pores (Fisher Scientific International Inc., Hampton, NH, USA) to remove particles and bacteria. The solution was prepared fresh for each injection.

\section{Emphysema models}

\section{(1) Cigarette smoke exposure}

The glass box used for modeling was made by ourselves and with the size of $(69 \mathrm{~cm} \times 47 \mathrm{~cm} \times 38 \mathrm{~cm})$, round hole with
$1 \mathrm{~cm}$ diameter at a density of 1 hole per $100 \mathrm{~cm}^{2}$ on the lid and 1 hole per $250 \mathrm{~cm}^{2}$ on four sides of the box. In the box, a partition with the same size holes at a density of 1 hole per $6 \mathrm{~cm}^{2}$ was placed in the middle of the box to divided it into two parts: the lower for cigarettes burning, and the upper for animal exposure to the smoke. Firstly, five cigarettes were burned at the same time with the smoke lasting for $15 \mathrm{~min}$. Secondly, the box was opened to let the animals rest for $5 \mathrm{~min}$. Then the first step was repeated. This process was referred to as one cycle of CS exposure. Mice were exposed for 2 cycles/day, 6 days/week for 12 weeks. The control group was fed in Hospital Experimental Animal Center of Central South University.

\section{(2) Intraperitoneal injection of CSE}

The emphysema model was established as previously described [9]. The total experimental period was four weeks. On day 1, 12 and 23, animal in control group was given an intraperitoneal injection of $0.3 \mathrm{ml} / 20 \mathrm{~g}$ PBS, and animal in CSE group was given an intraperitoneal injection of $0.3 \mathrm{ml} / 20 \mathrm{~g}$ CSE-PBS. On day 29 , the mice were disposed for lung function measurement, blood collection, broncholavolar lavage (BAL) and histomorphological detection of lung tissue.

\section{Lung function measurement}

Lung function was measured using small animal spirometer (PLY3211 system, Buxco Electronics, USA) as previously described with a minor modification [10]. Briefly, the mouse was weighed, anesthetized by intraperitoneal injection of $10 \%$ chloral hydrate $(3 \mathrm{ml} / \mathrm{kg} \mathrm{BW})$ and tracheostomized. The trachea was cannulated, and the cannula was connected to a computer-controlled small animal spirometer. Airway resistance (Raw), lung dynamic compliance (Cdyn), peak expiratory flow (PEF) and inspiratory time/ expiratory time $(\mathrm{Ti} / \mathrm{Te})$ were measured.

\section{Histomorphology detection of lung tissue}

After lung function measurement, animal was sacrificed by overdose of anesthetics. The lower left lobes of lungs were inflated with $4 \%$ paraformaldehyde at a constant pressure of $25 \mathrm{~cm} \mathrm{H}_{2} \mathrm{O}$, then fixed with $4 \%$ paraformaldehyde for $24 \mathrm{~h}$ [10]. Fixed lung was embedded in paraffin (Sigma, USA) and sectioned into 4- $\mu \mathrm{m}$ sections. The slices were stained with hematoxylin and eosin (H \& E) (Sigma, USA). Emphysema was quantified based on the measurement of the mean linear intercept (MLI) and destructive index (DI). The MLI and DI were measured as previously described [11]. Briefly, the MLI was measured by dividing the length of a line drawn across the lung section by a total number of intercepts counted within this line. The DI was calculated by dividing the defined destructive alveoli by the total number of alveoli. 


\section{Apoptosis assay of alveolar septum cells}

Terminal deoxynucleotidyl transferase-mediated dUTP nick end labeling (TUNEL) was performed to label the DNA-damaged cells using In Situ Cell Death Detection Kit (Roche Diagnostics, Mannheim, Germany) following the manufacturer's instructions. The apoptotic index (AI) was calculated as the percentage of TUNEL-positive nuclei.

Total and differential cells count in broncholavolar lavage fluid (BALF)

The left lung was clamped and the right lung was flushed 3 times with $1.0 \mathrm{~mL}$ PBS. BALF was pooled and the total volume was recorded. About $90 \%$ of the instilled PBS was collected from each animal. The BALF was immediately centrifuged for 10 minutes at $1500 \mathrm{rpm}(400 \times g)$ and $4^{\circ} \mathrm{C}$, and the cells were separated for counting. Cells were stained with Wright-Giemsa stain according to the manufacturer's instructions (Beyotime Institute of Biotechnology, China). Counts and differentials were manually determined using a standard hemocytometer. (Beyotime Institute of Biotechnology, China). Wright-Giemsa-stained slides were examined in a random sequence. 400 leukocytes were counted on each slide and measured by high microscopy at a magnification of $\times 1000$. The percentages of neutrophils (NEU) and macrophages (MAC) were analyzed.

\section{Measurement of SOD and IL-6 concentrations in serum}

The concentrations of SOD and IL- 6 in serum were measured with ELISA kits (R \& D Systems, Pittsburg, PA, USA and Jingmei Biotech Co. Ltd., Shenzhen, China, respectively) according to the manufacturers' instructions.

\section{Statistical analysis}

Analyses were performed using SPSS for Windows 16.0 (SPSS Inc., Chicago, IL, USA). All data were expressed as means \pm standard deviation. Analysis of differences among groups were performed using analysis of variance (one-way ANOVA), followed by post-hoc analysis as appropriate. Values of $P<0.05$ were considered statistically significant.

\section{Results}

\section{Lung function}

Raw was increased in mice induced by CS or CSE when compared with the respective controls $(P<0.01)$. Cdyn, $\mathrm{PEF}$ and $\mathrm{Ti} / \mathrm{Te}$ were decreased in mice induced by $\mathrm{CS}$ or CSE when compared with the respective controls $(P<0.01)$. There was no significant difference between CS group and CSE group in Raw, Cdyn, PEF or Ti/Te $(P>0.05)$ (Table 1$)$.

\section{Histomorphological changes of lung tissues}

Lung tissue of mice induced by CS or CSE exhibited enlarged alveolar space, thinner alveolar septum and destroyed alveolar wall (Figure 1). The MLI and DI in mice induced by CS or CSE were increased when compared
Table 1 Lung function

\begin{tabular}{|c|c|c|c|c|}
\hline & \multicolumn{2}{|c|}{ CS (group 1) } & \multicolumn{2}{|c|}{ CSE (group 2) } \\
\hline & $\begin{array}{l}\text { N1 } \\
(n=10)\end{array}$ & $\begin{array}{l}C 1 \\
(n=10)\end{array}$ & $\begin{array}{l}\text { N2 } \\
(n=10)\end{array}$ & $\begin{array}{l}C 2 \\
(n=10)\end{array}$ \\
\hline Raw & $0.42 \pm 0.06$ & $1.92 \pm 0.36 \star$ & $0.45 \pm 0.07$ & $2.05 \pm 0.39 \star$ \\
\hline \multicolumn{5}{|l|}{$\left(\mathrm{cmH}_{2} \mathrm{OmL} \mathrm{min}^{-1} \min ^{-1}\right)$} \\
\hline Cdyn $\left(\mathrm{mL} / \mathrm{cmH}_{2} \mathrm{O}\right)$ & $2.72 \pm 0.51$ & $1.05 \pm 0.22 \star$ & $2.25 \pm 0.37$ & $1.02 \pm 0.23 \star$ \\
\hline \multicolumn{5}{|l|}{$\operatorname{PEF}(\mathrm{mL} / \mathrm{s})$} \\
\hline \multirow[t]{2}{*}{$\mathrm{Ti} / \mathrm{Te}$} & $6.55 \pm 1.05$ & $4.37 \pm 0.76 \star$ & $6.06 \pm 0.71$ & $3.91 \pm 0.77 \star$ \\
\hline & $0.85 \pm 0.14$ & $0.60 \pm 0.11 \star$ & $0.88 \pm 0.11$ & $0.56 \pm 0.11 \star$ \\
\hline
\end{tabular}

Lung function was measured 12 weeks after the start of CS exposure (group 1) or 29 days after the start of intraperitoneal injection of CSE (group 2). CS, cigarette smoke; CSE, cigarette smoke extract; N1, controls of CS exposure group; C1, CS exposure group; N2, controls of intraperitoneal injection of CSE group; C2, intraperitoneal injection of CSE group; Raw, airway resistance; Cdyn, lung dynamic compliance; PEF, peak expiratory flow; Ti, inspiratory time; $\mathrm{Te}$, expiratory time. Valus are means \pm standard deviation, $\star P<0.01$ compared with the respective group $\mathrm{N}$.

with the respective controls $(P<0.01)$ (Figure 2$)$. There was no significant difference between CS group and CSE group in MLI or DI $(P>0.05)$.

\section{Apoptosis of alveolar septum cells}

The number of apoptotic alvelolar septum cells in mice induced by CS or CSE was increased when compared with the respective controls (Figure 3). The AI of alvelolar septum cells in mice induced by CS or CSE was higher than that of the respective controls $(P<0.01)$ (Figure 3). There was no significant difference between CS group and CSE group in AI $(P>0.05)$.

\section{Total and differential cells count in BALF}

As shown in Table 2, the number of total cells, MAC, NEU and the percentage of NEU (NEU\%) in mice induced by CS or CSE were higher than those in their respective controls $(P<0.01)$. There was no statistic difference in any parameters described above between CS group and CSE group $(P>0.05)$ (Table 2).

\section{SOD and IL- 6 concentrations in serum}

The SOD concentration in the serum of mice induced by CS $(215.91 \pm 39.44 \mathrm{U} / \mathrm{mL}, P<0.01)$ or CSE $(200.93 \pm 45.86$ $\mathrm{U} / \mathrm{mL}, P<0.01$ ) were lower than those in their respective controls $(272.33 \pm 31.26 \mathrm{U} / \mathrm{mL}$ and $284.08 \pm 36.09 \mathrm{U} / \mathrm{mL}$, respectively). There was no significant difference in SOD concentration $(P>0.05)$ between CS group and CSE group. The IL- 6 concentration in the serum of mice induced by CS $(73.54 \pm 16.02 \mathrm{pg} / \mathrm{mL}, \quad P<0.01)$ or CSE $(70.74 \pm$ $13.43 \mathrm{pg} / \mathrm{mL}, P<0.01)$ were higher than those in their respective controls $(8.88 \pm 1.56 \mathrm{pg} / \mathrm{mL}$ and $10.03 \pm 1.87 \mathrm{pg} /$ $\mathrm{mL}$, respectively). There was no significant difference in IL-6 concentration $(P>0.05)$ between CS group and CSE group (Figure 4). 

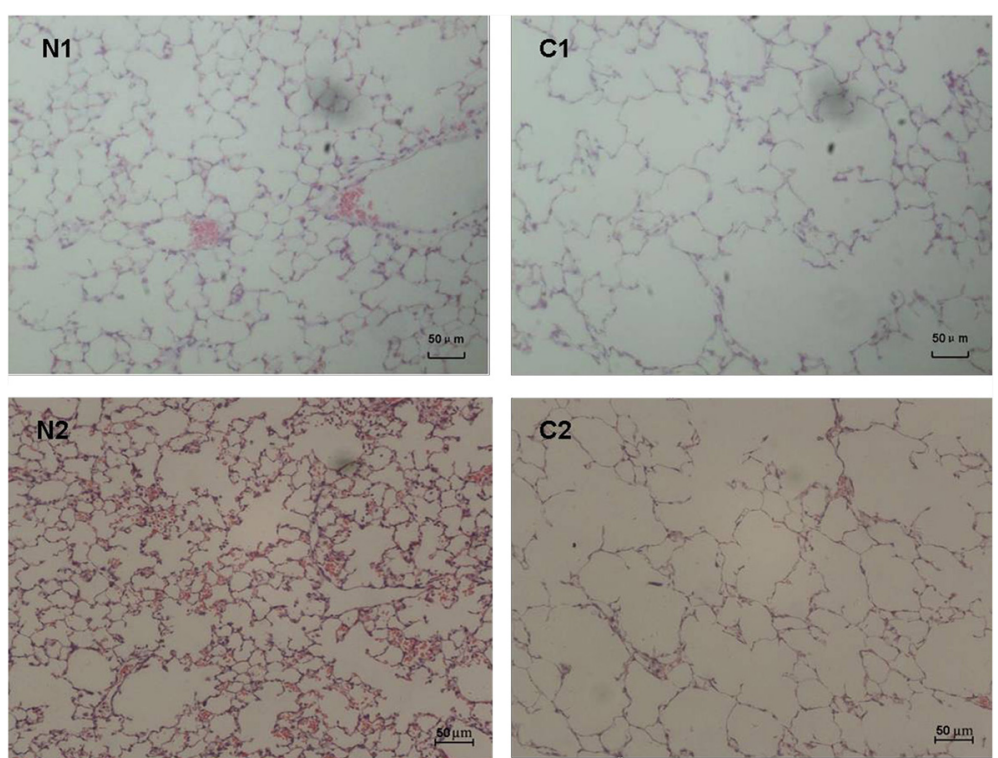

Figure 1 Lung histomorphology of C57BL/6 J mice induced by CS exposure and intraperitoneal injection of CSE ( $\times 100)$. Lung tissues of C57BL/6 J mice induced by CS exposure (C1) exhibited enlarged alveolar space, thinner alveolar septum, and destroyed alveolar wall when compared with those of the controls (N1). Lung tissues of C57BL/6 J mice induced by intraperitoneal injection of CSE (C2) also exhibited enlarged alveolar space, thinner alveolar septum, and destroyed alveolar wall when compared with those of the controls (N2). CS, cigarette smoke; CSE, cigarette smoke extract.

\section{Discussion}

The present study showed that both CS exposure and intraperitoneal injection of CSE could induce emphysema manifested in decreased lung function, enlarged alveolar space, destroyed alveolar wall, increased apoptosis in alveolar septum cells and increased inflammatory cells in BALF in mice. Meanwhile, the decreased SOD concentration and increased IL- 6 concentration in the serum could be observed in both CS exposure-induced emphysema and intraperitoneal injection of CSEinduced emphysema. More importantly, the changes described above induced by the two different methods were the same.

Pulmonary function is an important criterion for the evaluation of emphysema model. There was global strategy for the diagnosis, classification of COPD in human [12], but no for animal emphysema or COPD. The present study showed that mice induced by CS or CSE exhibited decreased lung function. Pulmonary function tests were considered to be less sensitive than morphometry and might detect only more severe degrees of airways remodeling or parenchymal destruction. Mild emphysema might
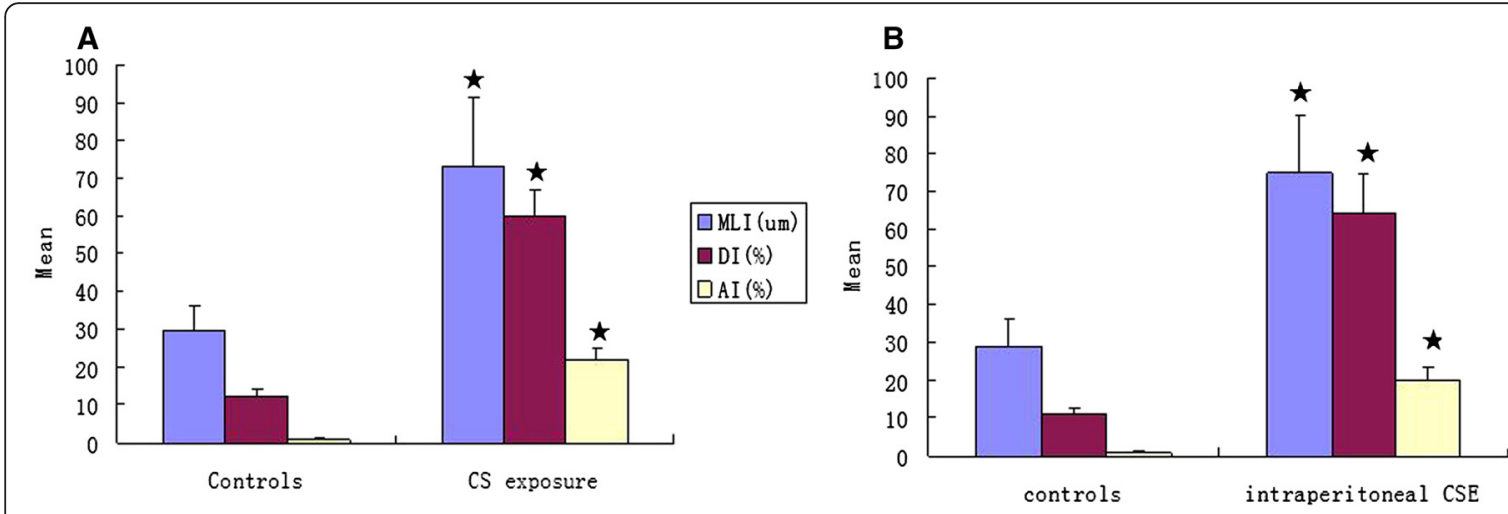

$\square \mathrm{DI}(\mathrm{\infty})$

$\square \mathrm{AI}(\%)$

Figure $2 \mathrm{MLI}, \mathrm{DI}$, and $\mathrm{Al}$ in C57BL/6 J mice induced by CS exposure (A) and that induced by intraperitoneal injection of CSE (B). MLI, mean linear intercept; DI, destructive index; $\mathrm{Al}$, apoptotic index; CS, cigarette smoke; CSE, cigarette smoke extract. $\star P<0.01$ compared with controls. 


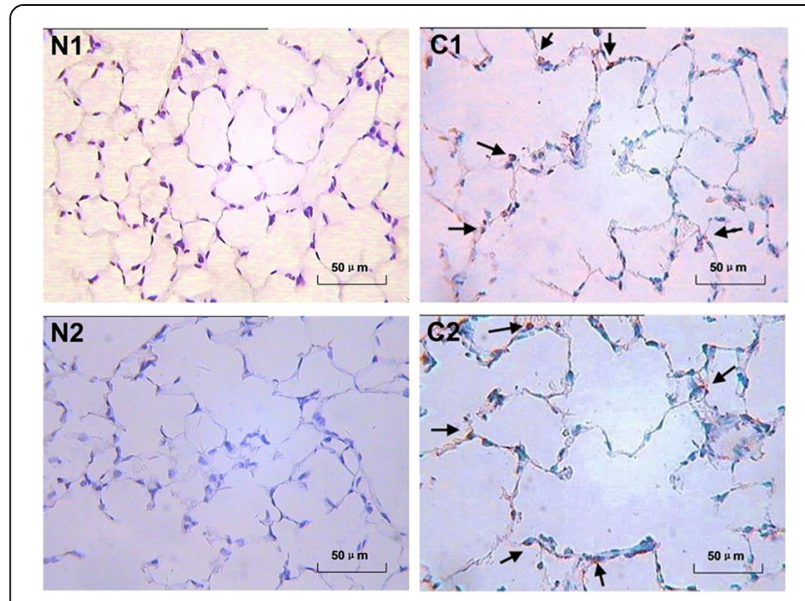

Figure 3 Apoptosis of alveolar septum cells in C57BL/6 J mice induced by CS exposure and that induced by intraperitoneal injection of CSE $(\times 400)$. The number of apoptotic alveolar septum cells in C57BL/6 J mice induced by cigarette smoke exposure (C1) was increased when compared with the controls (N1). The number of apoptotic alveolar septum cells in C57BL/6 J mice induced by intraperitoneal injection of cigarette smoke extract (C2) was also increased when compared with the controls (N2).

have normal lung function [13]. These viewpoints indicated that the emphysema models in the present study might represent severe cases of emphysema.

Ochs M. suggested that quantitative assessment of micro-structure was the only way to reliably demonstrate the presence of emphysematous alterations [14]. According to the American Thoracic Society, emphysema was defined as "abnormal, permanent enlargement of the airspaces distal to the terminal bronchiole, accompanied by destruction of their walls" [15]. This widely accepted definition was fulfilled in both CS exposureinduced emphysema and intraperitoneal injection of CSE-induced emphysema.

Apoptosis of alveolar septal cells plays an important role in the development of emphysema [16]. Apoptotic index (AI) reflects apoptosis status. In the present study, AI of alveolar septum cells in emphysema animals whether induced by CS exposure or intraperitoneal injection of CSE were significantly increased.

Our previous study showed that the inflamed airways of COPD patients contained several inflammatory cells including NEU and MAC [17]. In the present study, the increased inflammatory cells were also observed in BALF of all emphysema animal, whether induced by CS exposure or intraperitoneal injection of CSE.

Oxidative stress is an important mechanism in the pathogenesis of COPD. When the resident antioxidants are insufficient or fail to upregulate sufficiently to neutralize an increased oxidant burden, oxidative stress occurs. ROS contributes to a variety of adverse consequences, including cell apoptosis, inflammatory responses, and impaired tissue repair, and all of these processes are intimately associated with oxidative stress [18]. SOD could decrease markers of oxidative stress in patients with emphysema [19]. Extracellular SOD could protect against pulmonary emphysema and lung inflammation induced by cigarette smoke by decreasing oxidative fragmentation of the extracellular matrix [20]. IL-6 is a pro-inflammatory mediator [21] and is regarded as a COPD candidate gene [22]. IL-6 could promote the development of pulmonary emphysema associated with apoptosis in mice [23]. The important role of IL-6 in the pathogenesis of emphysema was further suggested by clinical studies demonstrating the elevated systemic IL-6 concentrations in patients with emphysema $[17,24]$. In the present study, the decreased SOD concentration and increased IL- 6 concentration in the serum were confirmed in the emphysema models whether induced by CS exposure or intraperitoneal injection of CSE.

To date, a large variety of emphysema animal models have been developed in various species including dogs, monkey, pigs, sheep, rabbits, guinea pigs, rats and mice [25-31]. Emphysema animal model has been established by exposure to smoking [32], intranasal instillation of elastase [33], intranasal instillation of LPS [34], exposure to sulfur dioxide [35], inhalation of ovalbumin dry powder [36], intravenous injection of hyaluronidase [37], genetic manipulation [38], and intraperitoneal injection

Table 2 Total and differential cells count in BALF

\begin{tabular}{|c|c|c|c|c|}
\hline & \multicolumn{2}{|l|}{ CS (group 1) } & \multicolumn{2}{|l|}{ CSE (group 2) } \\
\hline & N1 $(n=10)$ & $C 1(n=10)$ & N2 $(n=10)$ & $C 2(n=10)$ \\
\hline Total cells $\left(\times 10^{8} / \mathrm{L}\right)$ & $1.46 \pm 0.25$ & $5.35 \pm 1.05 \star$ & $1.46 \pm 0.23$ & $5.07 \pm 1.01 \star$ \\
\hline $\operatorname{MAC}\left(\times 10^{8} / \mathrm{L}\right)$ & $1.07 \pm 0.20$ & $3.34 \pm 0.66 \star$ & $1.31 \pm 0.20$ & $3.51 \pm 0.56 \star$ \\
\hline \multicolumn{5}{|l|}{ MAC\%(\%) } \\
\hline $\operatorname{NEU}\left(\times 10^{7} / L\right)$ & $71.82 \pm 13.85$ & $59.15 \pm 10.30 \star$ & $68.03 \pm 14.76$ & $51.07 \pm 10.62 \star$ \\
\hline \multirow[t]{2}{*}{ NEU\%(\%) } & $1.35 \pm 0.20$ & $13.01 \pm 2.23 \star$ & $1.45 \pm 0.19$ & $13.76 \pm 2.38 \star$ \\
\hline & $9.85 \pm 1.75$ & $19.95 \pm 3.46 \star$ & $9.67 \pm 1.59$ & $21.49 \pm 3.95 \star$ \\
\hline
\end{tabular}

BALF, broncholavolar lavage fluid; CS, cigarette smoke; CSE, cigarette smoke extract; N1, controls of CS exposure group; C1, CS exposure group; N2, controls of intraperitoneal injection of CSE group; C2, intraperitoneal injection of CSE group; MAC, macrophage; NEU, neutrophil. Valus are means \pm standard deviation, $\star P<0.01$ compared with the respective group $\mathrm{N}$. 

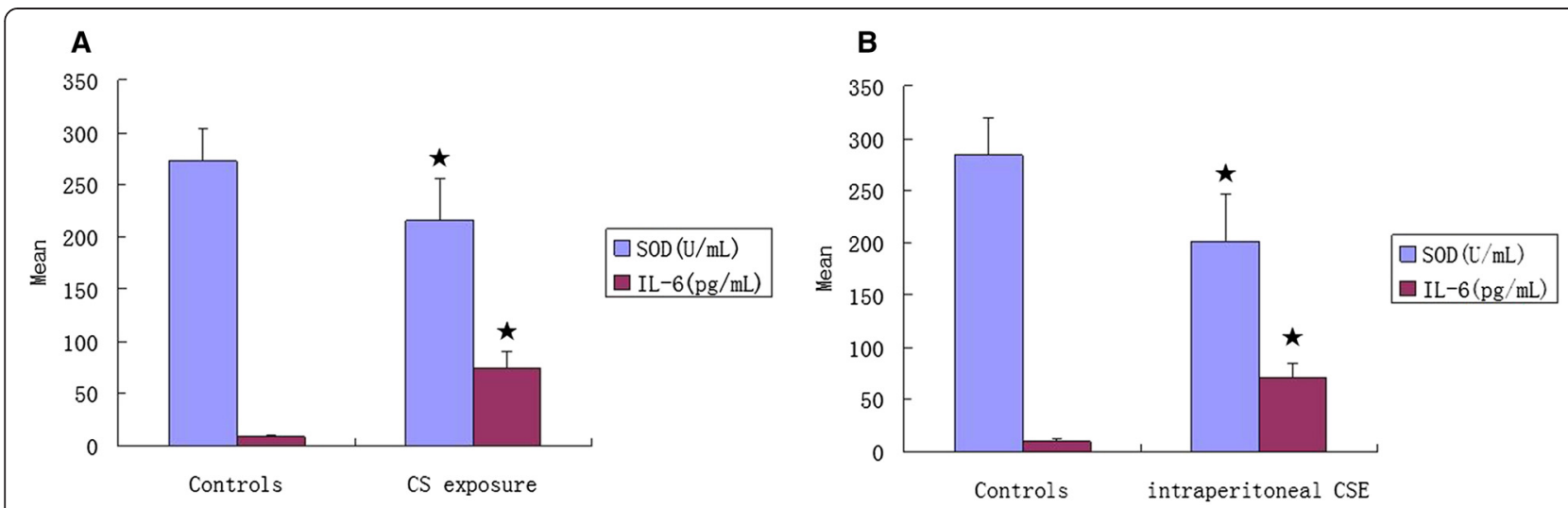

Figure 4 SOD and IL- 6 concentrations in serum of C57BL/6 J mice induced by CS exposure (A) and that induced by intraperitoneal injection of CSE (B). SOD, superoxide dismutase; IL-6, interleukin-6; CS, cigarette smoke; CSE, cigarette smoke extract. $\star P P 0.01$ compared with controls.

with xenogeneic endothelial cells [39], and intraperitoneal injection with CSE [6]. Among the emphysema animal models, mice have become very popular for experiment because their genome are much more like human being's than many other animals [40] and they offer the advantages of low cost, extensive gene/protein sequence/antibody availability, and, most important, the availability of numerous naturally occurring mouse strains with different reactions to smoke. But the study on the comparison of models is seldom.

Cigarette smoking is by far the most important risk factor for emphysema and COPD. CS induces significant increases in the generation of reactive oxygen species (ROS) [41]. ROS contributes to a variety of adverse consequences including cell apoptosis, inflammatory responses and impaired tissue repair [18]. Augmented apoptosis, impaired efferocytosis and abnormal tissue remodeling contribute to the chronic inflammatory response and tissue destruction in emphysema and COPD [42]. Interestingly, the present study showed that there was no significant difference between mice induced by CS exposure and that induced by intraperitoneal injection of CSE in lung function, histomorphology, apoptosis of alveolar septum cells, total and differential inflammatory cells count in BALF, SOD and IL-6 concentrations in serum. These results suggested that the modeled effects of the two different modeling methods, CS exposure and intraperitoneal injection of CSE, were equal.

CS exposure was looked as the traditional method of long-term modeling of emphysema. The various times spent on modeling might be due to the different kind of cigarette, different exposure mode, duration and frequency, different smoke density, different species and age of animals and so on. Because of the long modeling time, inconsistence and unstability, researchers have constantly explored new modeling methods. As the surrogate of CS, CSE could be considered to play the same role as CS in emphysema and COPD. CSE could decrease the function of endothelial progenitor cells (EPCs) [43], induce the apoptosis of pulmonary endothelial cells [44]. Intraperitoneal injection of CSE is a relatively new method of short-term modeling of emphysema, which was firstly reported by TarasevicieneStewart et al. in 2007 [45]. Taraseviciene-Stewart et al. reported the emphysema model induced by intraperitoneal injection with xenogeneic endothelial cells in 2005 [39], and then used CSE instead of xenogeneic endothelial cells. The mechanism of intraperitoneal CSE-induced emphysema model is under disscusion. Taraseviciene-Stewart et al. hypothesized that CSE could act as an antigen triggering an immune response as well as oxidative stress that induced emphysema [45]. Zhang Y et al. thought that the mechanism of intraperitoneal CSE-induced model was link to apoptosis of pulmonary vascular endothelium. Intraperitoneal injection of CSE, corresponding to systemic delivery of CSE, reduced the biological antioxidant activity in BALF causing direct alveolar septum cells apoptosis and endothelium damage, which allowed inflammatory cells to infiltrate in the lung tissue [9]. It is unclear whether all pathophysiologically relevant mechanisms in this model are shared with the conventional model in which cigarette smoke is inhaled over a period of several months. The problem whether CSE impairs lung tissue targetedly making inflammatory cells homing in focus or the systemic inflammatory cells induced by CSE infiltrate in the lung tissue through the impaired endothelium needs further study. Systemic inflammatory process could affect lung tissue directly by releasing cytokines and chemokines or indirectly by activating lung inflammatory cells. More than one pathway might be operational at one time.

Although mice and humans share many basic physiological processes, specific differences in lung structure, function and immunology between humans and mice have to be taken into consideration. Even within mice, different strains exhibit different sensitivities to the development of emphysema [46]. None of the models reproduces the exact 
changes seen in humans, each has its own advantages and disadvantages. Although emphysema induced by intraperitoneal injection of CSE was similar to COPD in human in lung function, inflammatory cells in BALF, histomophology of lung tissue, we called it cautiously the "emphysema model", not "COPD model", on account of the modeling method. In fact, it is impossible for human to "smoke" by intraperitoneal injection of CSE. Therefore, it would not be known that whether this method could induce emphysema or even COPD in human.

\section{Conclusion}

The present study demonstrated that emphysema with decreased lung function, enlarged alveolar space, destroyed alveolar wall, apoptosis of alveolar septum cells, chronic inflammation in lung, decreased SOD concentration and increased IL-6 concentration in serum could be duplicated in mice induced by CS exposure or intraperitoneal injection of CSE. More importantly, the effectiveness of the two different modeling methods were equal.

\section{Abbreviations}

Al: Apoptotic index; BALF: Broncholavolar lavage fluid; Cdyn: Lung dynamic compliance; COPD: Chronic obstructive pulmonary disease; CS: Cigarette smoke; CSE: Cigarette smoke extract; DI: Mean linear intercept; EPCs: Endothelial progenitor cells; IL-6: Interleukin-6; MAC: Macrophage; MLI: Mean linear intercept; NEU: Neutrophil; PEF: Peak expiratory flow; Raw: Airway resistance; ROS: Reactive oxygen species; SOD: Superoxide dismutase; Te: Expiratory time; Ti: Inspiratory time.

\section{Competing interests}

The authors declare that they have no competing interests.

\section{Authors' contributions}

$\mathrm{ZHH}$ conceived the study, performed the experiment, data analysis, and drafted the manuscript. PC coordinated the study. YC conceived the study and critically revised the manuscript. SDH, JRY, HLZ and JC performed the experiment and helped in data collection. All authors read and approved the final manuscript.

\section{Acknowledgements}

This study was supported by the Natural Science Foundation of China (Number: 81070039).

\section{Author details}

'Intensive Care Unit, the Second Xiangya Hospital, Central-South University, Changsha, Hunan 410011, China. ${ }^{2}$ Department of Respiratory Medicine, The Second Xiangya Hospital, Central-South University, Changsha, Hunan 410011, China. ${ }^{3}$ Division of Respiratory Disease, Department of Internal Medicine, The Second Xiangya Hospital, Central-South University, Changsha, Hunan 410011, China. ${ }^{4}$ Department of Respiratory Medicine, Hunan Provincial People's Hospital, Changsha, Hunan 410005, China.

Received: 12 August 2014 Accepted: 15 March 2015

Published online: 25 March 2015

\section{References}

1. Fuschillo S, Martucci M, Donner CF, Balzano G. Airway bacterial colonization: the missing link between COPD and cardiovascular events? Respir Med. 2012;106:915-23.

2. Miravitlles M. Cough and sputum production as risk factors for poor outcomes in patients with COPD. Respir Med. 2011;105:1118-28.

3. Pryor WA, Stone K. Oxidants in cigarette smoke. Radicals, hydrogen peroxide, peroxynitrate, and peroxynitrite. Ann N Y Acad Sci. 1993;686:12-27.
4. Xu CB, Lei Y, Chen Q, Pehrson C, Larsson L, Edvinsson L. Cigarette smoke extracts promote vascular smooth muscle cell proliferation and enhances contractile responses in the vasculature and airway. Basic Clin Pharmacol Toxicol. 2010;107:940-8.

5. Zhang $H$, Chen $P$, Zeng $H$, Zhang $Y$, Peng $H$, Chen $Y$, et al. Protective effect of demethylation treatment on cigarette smoke extract-induced mouse emphysema model. J Pharmacol Sci. 2013;123:159-66.

6. He S, He Z, Chen Y, Ye J, Zong D, Zhang Y, et al. C-Kit/c-Kit ligand interaction of bone marrow endothelial progenitor cells is influenced in acigarette smoke extract-induced emphysema model. Exp Lung Res. 2013;39:258-67.

7. World Medical Association; American Physiological Society. Guiding principles for research involving animals and human beings. Am J Physiol Regul Integr Comp Physiol. 2002;283:R281-3.

8. Chen Y, Hanaoka M, Droma Y, Chen P, Voelkel NF, Kubo K. Endothelin-1 receptor antagonists prevent the development of pulmonary emphysema in rats. Eur Respir J. 2010;35:904-12.

9. Zhang Y, Cao J, Chen Y, Chen P, Peng H, Cai S, et al. Intraperitoneal injection of cigarette smoke extract induced emphysema, and injury of cardiac and skeletal muscles in BALB/C mice. Exp Lung Res. 2013;39:18-31.

10. Yao H, Chung S, Hwang JW, Rajendrasozhan S, Sundar IK, Dean DA, et al. SIRT1 protects against emphysema via FOXO3-mediated reduction of premature senescence in mice. J Clin Invest. 2012;122:2032-45.

11. Chen $Y$, Hanaoka M, Chen P, Droma Y, Voelkel NF, Kubo K. Protective effect of beraprost sodium, a stable prostacyclin analog, in the development of cigarette smoke extract-induced emphysema. Am J Physiol Lung Cell Mol Physiol. 2009;296:L648-56.

12. Vestbo J, Hurd SS, Agustí AG, Jones PW, Vogelmeier C, Anzueto A, et al. Global strategy for the diagnosis, management, and prevention of chronic obstructive pulmonarydisease: GOLD executive summary. Am J Respir Crit Care Med. 2013;187:347-65.

13. Wright JL, Cosio M, Churg A. Animal models of chronic obstructive pulmonary disease. Am J Physiol Lung Cell Mol Physiol. 2008;295:L1-15.

14. Ochs M. Estimating structural alterations in animal models of lung emphysema. Is there a gold standard? Ann Anat. 2014;196:26-33.

15. American Thoracic Society. Standards for the diagnosis and care of patients with chronic obstructive pulmonary disease. Am J Respir Crit Care Med. 1995;152:S77-121.

16. Yang Q, Underwood MJ, Hsin MK, Liu XC, He GW. Dysfunction of pulmonary vascular endothelium in chronic obstructive pulmonary disease: basic considerations for future drug development. Curr Drug Metab. 2008:9:661-7.

17. He Z, Chen Y, Chen P, Wu G, Cai S. Local inflammation occurs before systemic inflammation in patients with COPD. Respirology. 2010;15:478-84.

18. Yao H, Rahman I. Current concepts on oxidative/carbonyl stress, inflammation and epigenetics in pathogenesis of chronic obstructive pulmonary disease. Toxicol Appl Pharmacol. 2011;254:72-85.

19. Hillas G, Nikolakopoulou S, Hussain S, Vassilakopoulos T. Antioxidants and mucolytics in COPD management: when (if ever) and in whom? Curr Drug Targets. 2013;14:225-34.

20. Yao H, Arunachalam G, Hwang JW, Chung S, Sundar IK, Kinnula VL, et al. Extracellular superoxide dismutase protects against pulmonary emphysema by attenuating oxidative fragmentation of ECM. Proc Natl Acad Sci U S A. 2010;107:15571-6.

21. Biffl WL, Moore EE, Moore FA, Barnett Jr CC, Carl VS, Peterson VN. Interleukin-6 delays neutrophil apoptosis. Arch Surg. 1996;131:24-30.

22. Yanbaeva DG, Dentener MA, Spruit MA, Houwing-Duistermaat JJ, Kotz D, Passos VL, et al. IL6 and CRP haplotypes are associated with COPD risk and systemic inflammation: a case-control study. BMC Med Genet. 2009;10:23.

23. Ruwanpura SM, McLeod L, Miller A, Jones J, Bozinovski S, Vlahos R, et al. Interleukin-6 promotes pulmonary emphysema associated with apoptosis in mice. Am J Respir Cell Mol Biol. 2011;45:720-30.

24. Bozinovski S, Hutchinson A, Thompson M, Macgregor L, Black J, Giannakis E, et al. Serum amyloid a is a biomarker of acute exacerbations of chronic obstructive pulmonary disease. Am J Respir Crit Care Med. 2008;177:269-78.

25. Martin JG, Tamaoka M. Rat models of asthma and chronic obstructive lung disease. Pulm Pharmacol Ther. 2006;19:377-85.

26. Brusselle GG, Bracke KR, Maes T, D'hulst Al, Moerloose KB, Joos GF, et al. Murine models of COPD. Pulm Pharmacol Ther. 2006;19:155-65.

27. Plopper CG, Hyde DM. The non-human primate as a model for studying COPD and asthma. Pulm Pharmacol Ther. 2008;21:755-66. 
28. Chapman RW. Canine models of asthma and COPD. Pulm Pharmacol Ther. 2008;21:731-42.

29. Abraham WM. Modeling of asthma, COPD and cystic fibrosis in sheep. Pulm Pharmacol Ther. 2008;21:743-54.

30. Mahadeva R, Shapiro SD. Chronic obstructive pulmonary disease * 3 : experimental animal models of pulmonary emphysema. Thorax. 2002;57:908-14.

31. Wright JL, Churg A. Animal models of cigarette smoke-induced COPD. Chest. 2002;122(6 suppl):S301-6.

32. Givi ME, Peck MJ, Boon L, Mortaz E. The role of dendritic cells in the pathogenesis of cigarette smoke-induced emphysema in mice. Eur J Pharmacol. 2013;721:259-66.

33. Longhini-Dos-Santos N, Barbosa-de-Oliveira VA, Kozma RH, Faria CA, Stessuk $T$, Frei $F$, et al. Cell therapy with bone marrow mononuclear cells in elastase-induced pulmonary emphysema. Stem Cell Rev. 2013;9:210-8.

34. Pera T, Zuidhof AB, Smit M, Menzen MH, Klein T, Flik G, et al. Arginase inhibition prevents inflammation and remodeling in a guinea pig model of chronic obstructive pulmonary disease. J Pharmacol Exp Ther. 2014;349:229-38.

35. Wagner U, Staats P, Fehmann HC, Fischer A, Welte T, Groneberg DA. Analysis of airway secretions in a model of sulfur dioxide induced chronic obstructive pulmonary disease (COPD). J Occup Med Toxicol. 2006;1:12.

36. Misaka S, Sato H, Yamauchi Y, Onoue S, Yamada S. Novel dry powder formulation of ovalbumin for development of COPD-like animal model: physicochemical characterization and biomarker profiling in rats. Eur J Pharm Sci. 2009;37:469-76.

37. Tazaki G, Kondo T, Tajiri S, Tsuji C, Shioya S, Tanigaki T. Functional residual capacity and airway resistance in rats of COPD model induced by systemic hyaluronidase. Tokai J Exp Clin Med. 2006;31:125-7.

38. Baron RM, Choi AJ, Owen CA, Choi AM. Genetically manipulated mouse models of lung disease: potential and pitfalls. Am J Physiol Lung Cell Mol Physiol. 2012;302:L485-97.

39. Taraseviciene-Stewart L, Scerbavicius R, Choe KH, Moore M, Sullivan A Nicolls MR, et al. An animal model of autoimmune emphysema. Am J Respir Crit Care Med. 2005:171:734-42.

40. Pennisi E. Genomics: sequence tells mouse, human genome secrets. Science. 2002;298:1863-5.

41. Jeong YY, Park HJ, Cho YW, Kim EJ, Kim GT, Mun YJ, et al. Aged red garlic extract reduces cigarette smoke extract-induced cell death in human bronchial smooth muscle cells by increasing intracellular glutathione levels. Phytother Res. 2012;26:18-25.

42. Tzortzaki EG, Papi A, Neofytou E, Soulitzis N, Siafakas NM. Immune and genetic mechanisms in COPD: possible targets for therapeutic interventions. Curr Drug Targets. 2013;14:141-8.

43. He ZH, Chen P, Chen Y, Zhu YQ, He SD, Ye JR, et al. Dual effects of cigarette smoke extract on proliferation of endothelial progenitor cells and the protective effect of 5-aza-2'-deoxycytidine on EPCS against the damage caused by CSE. BioMed Res Int. 2014:2014:640752.

44. Nana-Sinkam SP, Lee JD, Sotto-Santiago S, Stearman RS, Keith RL, Choudhury Q, et al. Prostacyclin prevents pulmonary endothelial cell apoptosis induced by cigarette smoke. Am J Respir Crit Care Med. 2007; 175:676-85.

45. Taraseviciene-Stewart L, Kraskauskas D, Lee JH, Hanaoka M, Burns N, Parr J, et al. Cigarette smoke extract (CSE)-induced emphysema in mice. Am J Respir Crit Care Med. 2007;175:A529.

46. Yao H, Edirisinghe I, Rajendrasozhan S, Yang SR, Caito S, Adenuga D, et al. Cigarette smoke-mediated inflammatory and oxidative responses are strain-dependent in mice. Am J Physiol Lung Cell Mol Physiol. 2008:294:L1174-86.

\section{Submit your next manuscript to BioMed Central and take full advantage of:}

- Convenient online submission

- Thorough peer review

- No space constraints or color figure charges

- Immediate publication on acceptance

- Inclusion in PubMed, CAS, Scopus and Google Scholar

- Research which is freely available for redistribution

Submit your manuscript at www.biomedcentral.com/submit 